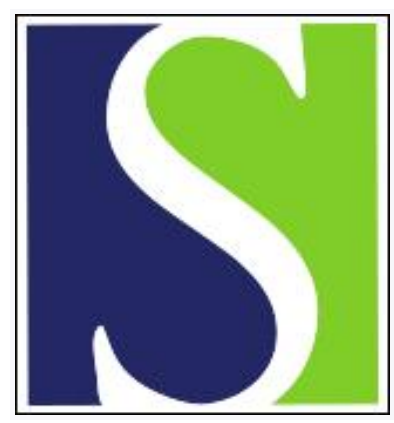

Scand J Work Environ Health 2016;42(1):52-60

https://doi.org/10.5271/sjweh.3538

Published online: 08 Dec 2015, Issue date: 01 Jan 2016

Occupational risk factors for endometriosis in a cohort of flight attendants

by Johnson CY, Grajewski B, Lawson CC, Whelan EA, Bertke SJ, Tseng C-Y

Flight attendants were no more likely to report endometriosis than teachers. Cosmic radiation, working during sleeping hours, and ergonomic factors were not associated with endometriosis among flight attendants; however, the risk was increased among flight attendants who worked greater numbers of flight segments per year.

Affiliation: National Institute for Occupational Safety and Health, 1090 Tusculum Ave MS R-15, Cincinnati, OH, 45226, USA. cyjohnson@cdc.gov

Refers to the following text of the Journal: 2009;35(3):233-240

Key terms: circadian disruption; cohort; cohort study; endometriosis; flight attendant; occupational risk; radiation; risk factor; work schedule

This article in PubMed: www.ncbi.nlm.nih.gov/pubmed/26645630

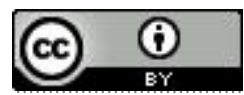




\title{
Occupational risk factors for endometriosis in a cohort of flight attendants
}

\author{
by Candice Y Johnson, PhD, ${ }^{1,2}$ Barbara Grajewski, PhD, ${ }^{1}$ Christina C Lawson, PhD, ${ }^{1}$ Elizabeth A Whelan, \\ PhD, ${ }^{1}$ Stephen J Bertke, PhD, ${ }^{1}$ Chih-Yu Tseng, MS ${ }^{1}$
}

\begin{abstract}
Johnson CY, Grajewski B, Lawson CC, Whelan EA, Bertke SJ, Tseng C-Y. Occupational risk factors for endometriosis in a cohort of flight attendants. Scand J Work Environ Health. 2016;42(1):52-60. doi:10.5271/sjweh:3538.
\end{abstract}

\begin{abstract}
Objectives This study aimed to (i) compare odds of endometriosis in a cohort of flight attendants against a comparison group of teachers and (ii) investigate occupational risk factors for endometriosis among flight attendants.

Methods We included 1945 flight attendants and 236 teachers aged 18-45 years. Laparoscopically confirmed endometriosis was self-reported via telephone interview, and flight records were retrieved from airlines to obtain work schedules and assess exposures for flight attendants. We used proportional odds regression to estimate adjusted odds ratios $\left(\mathrm{OR}_{\mathrm{adj}}\right)$ and $95 \%$ confidence intervals $(95 \% \mathrm{CI})$ for associations between exposures and endometriosis, adjusting for potential confounders.
\end{abstract}

Results Flight attendants and teachers were equally likely to report endometriosis $\left(\mathrm{OR}_{\mathrm{adj}} 1.0,95 \% \mathrm{CI} 0.5-2.2\right)$. Among flight attendants, there were no clear trends between estimated cosmic radiation, circadian disruption, or ergonomic exposures and endometriosis. Greater number of flight segments (non-stop flights between two cities) per year was associated with endometriosis $\left(\mathrm{OR}_{\mathrm{adj}} 2.2,1.1-4.2\right.$ for highest versus lowest quartile, $\mathrm{P}$ trend= 0.02 ) but block hours (taxi plus flight time) per year was not $\left(\mathrm{OR}_{\mathrm{adj}} 1.2,95 \% \mathrm{CI} 0.6-2.2\right.$ for highest versus lowest quartile, $\mathrm{P}$ trend $=0.38$ ).

Conclusion Flight attendants were no more likely than teachers to report endometriosis. Odds of endometriosis increased with number of flight segments flown per year. This suggests that some aspect of work scheduling is associated with increased risk of endometriosis, or endometriosis symptoms might affect how flight attendants schedule their flights.

Key terms circadian disruption; cohort study; radiation; work schedule.

Endometriosis is one of the most common gynecological conditions resulting in hospitalization in the United States (1). Endometriosis occurs when endometrial tissue is present outside of the uterus, such as on the ovaries, fallopian tubes, or bladder (2). Menstrual bleeding at these sites causes inflammation and promotes tissue scarring and adhesion, leading to chronic pelvic pain and impaired fertility $(2,3)$. Women with endometriosis report a lower health-related quality of life than unaffected women and lose an average of nearly 11 hours per week of work productivity due to their symptoms (4).

The etiology of endometriosis remains poorly understood. Risk factors identified fairly consistently in epidemiologic studies include low body mass index (BMI), early age at menarche, short menstrual cycles, and lighter skin pigmentation (3, 5-7). Recently, a study identified women working as flight attendants as having a higher risk of endometriosis than women in other occupational groups, although the study was unable to investigate specific occupational risk factors that might be responsible for this increased risk (8). Flight attendants have a unique combination of occupational exposures - including cosmic ionizing radiation, circadian disruption, and ergonomic factors - that might influence reproductive health (9).

Spending much of their workday at commercial aircraft altitudes, flight attendants have greater exposure to ionizing radiation from cosmic and solar radiation

1 National Institute for Occupational Safety and Health, Centers for Disease Control and Prevention, Cincinnati, OH, USA

2 Epidemic Intelligence Service, Centers for Disease Control and Prevention, Atlanta, GA, USA.

Correspondence to: Candice Johnson, National Institute for Occupational Safety and Health, 1090 Tusculum Ave MS R-15, Cincinnati, OH, 45226, USA. [E-mail: cyjohnson@cdc.gov] 
than workers on the ground (9). The potential effects of chronic, low doses of cosmic ionizing radiation experienced by flight crew on risk of endometriosis are unknown. Flight attendants often work during their normal sleep hours or cross multiple time zones, leading to circadian disruption. Two studies have reported higher risks of endometriosis among women working night shifts compared to women working days, raising the possibility that circadian disruption is associated with endometriosis $(10,11)$. Job duties of flight attendants also include heavy lifting, pulling and pushing, and prolonged standing; these occupational ergonomic factors have not yet been investigated in association with endometriosis.

In this study, we compare the risk of endometriosis between flight attendants and a comparison group of teachers and examine occupational risk factors for endometriosis in a cohort of flight attendants.

\section{Methods}

We used data from a retrospective cohort study of reproductive health among female flight attendants, the original aim of which was to estimate cosmic ionizing radiation and circadian disruption exposures among flight attendants and their potential association with adverse reproductive health outcomes such as miscarriage and menstrual function (12). Female flight attendants aged 18-45 years were selected from employee lists from three US commercial airline hubs in Detroit, Miami, and Seattle. At the same time that the flight attendants were selected for the study, a comparison group of female classroom teachers (aged 18-45 years and teaching grades 5-12) was selected from rosters provided by local school districts in the same three geographic regions as the flight attendants. Although other occupational groups were considered for the comparison population, teachers were chosen because they are a female-dominated occupational group with infrequent air travel, they are exposed to few reproductive health hazards at work, and there were detailed employment records available (13). Based on data from the Association of Flight Attendants and the 1988 National Survey of Family Growth, teachers and flight attendants were similar with respect to age, race, education, and parity, suggesting they would be an appropriate comparison group. Due to the higher risk of respiratory infections with close contact with younger children, teachers of younger students were excluded because of the original study's secondary aim to investigate respiratory infections.

Eligible women worked for at $\geq 1$ month as a flight attendant or teacher during the study period of 1 August 1992 to 31 July 1996 . Because the primary objec- tive of the study was to investigate pregnancy-related outcomes, only women who were married and who had not had a hysterectomy or tubal ligation prior to 1 August 1992 were included. Between 1 November 1999 and 30 April 2001, potentially eligible women completed a computer-assisted telephone interview to determine eligibility and, if eligible, to answer questions on their work duties, menstrual and reproductive histories (including endometriosis diagnosis), sleep habits, and sociodemographic characteristics. Figure 1 illustrates the timing of collection of various data elements in the study. The Institutional Review Board of the National Institute for Occupational Safety and Health approved this study. All participants provided informed consent.

\section{Outcome}

In the interview (1999-2001), women were asked: "Has a doctor ever told you that you had endometriosis?". If the response was positive, they were asked the month and year of diagnosis and whether the diagnosis was confirmed by laparoscopy. Only laparoscopicallyconfirmed cases with known dates of diagnosis were considered endometriosis cases.

\section{Exposures}

Individual flight records were obtained from study airlines for flights between 1 August 1992 and 31 July 1996. The records included data about each flight segment (travel between two cities without stops) flown by each flight attendant during the study period. We also obtained data from the airlines on uncompensated passenger flights (flights taken at reduced cost) and obtained information from both airlines and self-report on commuter flights (flights used to commute to the airport of the flight attendant's next worked flight), which made up approximately $15 \%$ of flight segments.

Work characteristics. Airline records (1992-1996) were used to determine the average number of block hours (airborne plus taxi time) flown per year, the average number of flight segments flown per year, and the median number of flight segments flown per flight day for each flight attendant. Block hours for uncompensated passenger flights and commuter flights were unavailable from the airline records, and so the median block hours for that route, based on the work flight segments, was used for these estimates.

Circadian disruption. We calculated two measures of circadian disruption using airline records (1992-1996): number of time zones crossed (without regard to travel direction), and hours of travel during the standard sleep interval (time spent flying between 22:00-08:00 hours 


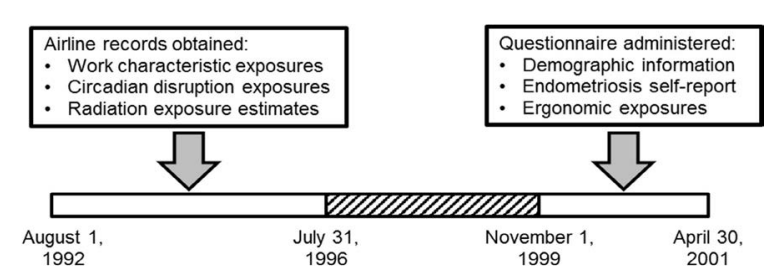

Figure 1. Timeline of collection of exposures from airline records and questionnaire for flight attendants and teachers.

in the time zone of the flight attendant's domicile) (14, $15)$. From these measures, three metrics were created: the average number of time zones crossed per year, the median number of time zones crossed per flight segment, and the average yearly hours of flight during the standard sleep interval.

Radiation. From airline records (1992-1996), we estimated the dose of galactic cosmic ionizing radiation (background radiation originating outside the solar system) flight attendants experienced during each flight segment using the Federal Aviation Administration's computer program CARI6P (screen version 9/17/2005) (16). To do this, regression models of a previously described algorithm were used to create CARI inputs from work histories $(15,17)$. For each flight segment, the following data were obtained directly from records, calculated, or estimated using the regression models: date flight began, origin and destination cities (city pairs), block hours, and local arrival and departure times. We separately estimated absorbed dose in microgray ( $\mu \mathrm{Gy}$ ) and effective dose in microsieverts $(\mu \mathrm{Sv}$, proton weighting factor $=$ 2) for electromagnetic showers, muons, neutrons, pions, protons, and total absorbed dose $(15,17)$. Yearly dose estimates were calculated by dividing the cumulative dose from the flight records by the number of years of flight records available. Estimation of galactic cosmic radiation dose was completed for more than $99.9 \%$ of 1984285 flight segments. We did not include radiation from solar particle events in the yearly average radiation dose estimates because these are transient sources of radiation and only two were assessed between 1992 and 1996 (18).

Ergonomic factors. During the interview (1999-2001), participants were asked to report their overall physical effort at work (very light, somewhat light, moderate, somewhat hard, very hard), occupational lifting of $\geq 15$ pounds $(<1,1-5,6-10,>10$ times per day), standing and walking at work $(<1,1-4,5-8,>8$ hours per day), bending $(<1,1-25,26-50,51-75,>75$ times per day), and pushing or pulling $\geq 15$ pounds at work $(<1,1-9$, $10-19,20-30,>30$ times per day).

\section{Statistical analysis}

We used a time-to-event analysis with months as time scale. Time zero was assigned as the flight attendant's date of birth to take into account effects of age in the time scale. We calculated person-months at risk using as a start date age in months at either 30 days past 1 August 1992 or 30 days past the hire date (whichever came later) and, as the end date, the age in months at endometriosis diagnosis or censoring event (which ever came first). Women were censored at the date of whichever of the following events occurred first: interview, termination of employment, hysterectomy or oophorectomy, last menstrual period (if menstrual periods had ceased), or age 45 (proxy for the beginning of the peri-menopausal period and therefore the end of the risk period for endometriosis). Women who reported non-laparoscopically-confirmed endometriosis were not considered endometriosis cases; they were included in the analysis and censored at their date of diagnosis. The 30-day delay in counting person-time was included because participants had to be employed for $\geq 1$ month before being eligible for the study.

To create a cohort of women at risk for endometriosis and working as of 1 August 1992, we excluded women from the analysis for the following reasons: did not fly during the study period $(\mathrm{N}=19)$; missing date of birth $(\mathrm{N}=1)$; missing hire date $(\mathrm{N}=49)$; hire date was after the study period ended ( $\mathrm{N}=67)$; did not answer question on endometriosis diagnosis $(\mathrm{N}=2)$; date of endometriosis diagnosis missing for cases $(\mathrm{N}=7)$; endometriosis diagnosis date for cases was before the study start date $(\mathrm{N}=112)$; endometriosis diagnosis date for cases was before the hire date $(\mathrm{N}=1)$; date of hysterectomy was before the hire date $(\mathrm{N}=1)$; missing hysterectomy date $(\mathrm{N}=1)$; if menstrual periods had ceased, the last menstrual period was before the hire date $(\mathrm{N}=4)$, before the study start $(\mathrm{N}=3)$, or the date of last menstrual period was missing $(\mathrm{N}=19)$; or flight attendants' work history was too inconsistent or had too many gaps to estimate metrics $(\mathrm{N}=135)$ (figure 2).

Crude and multivariable discrete-time proportional odds models were fit in PROC PHREG with the TIES=DISCRETE option in SAS 9.3 (SAS Institute, Cary, NC, USA) to handle tied failure times. We conditioned on age at start of the study period to account for left truncation. We estimated odds ratios (OR) and 95\% confidence intervals $(95 \% \mathrm{CI})$ for associations between each exposure and endometriosis. We tested the proportional odds assumption by including a time-dependent interaction term in the model and performing a Wald type 3 chi-square test, with $\mathrm{P}<0.05$ indicating violation of the assumption. $\mathrm{P}$ for linear trend was calculated using either the midpoint of each category (continuous variables) or a set of ordinal variables corresponding to 


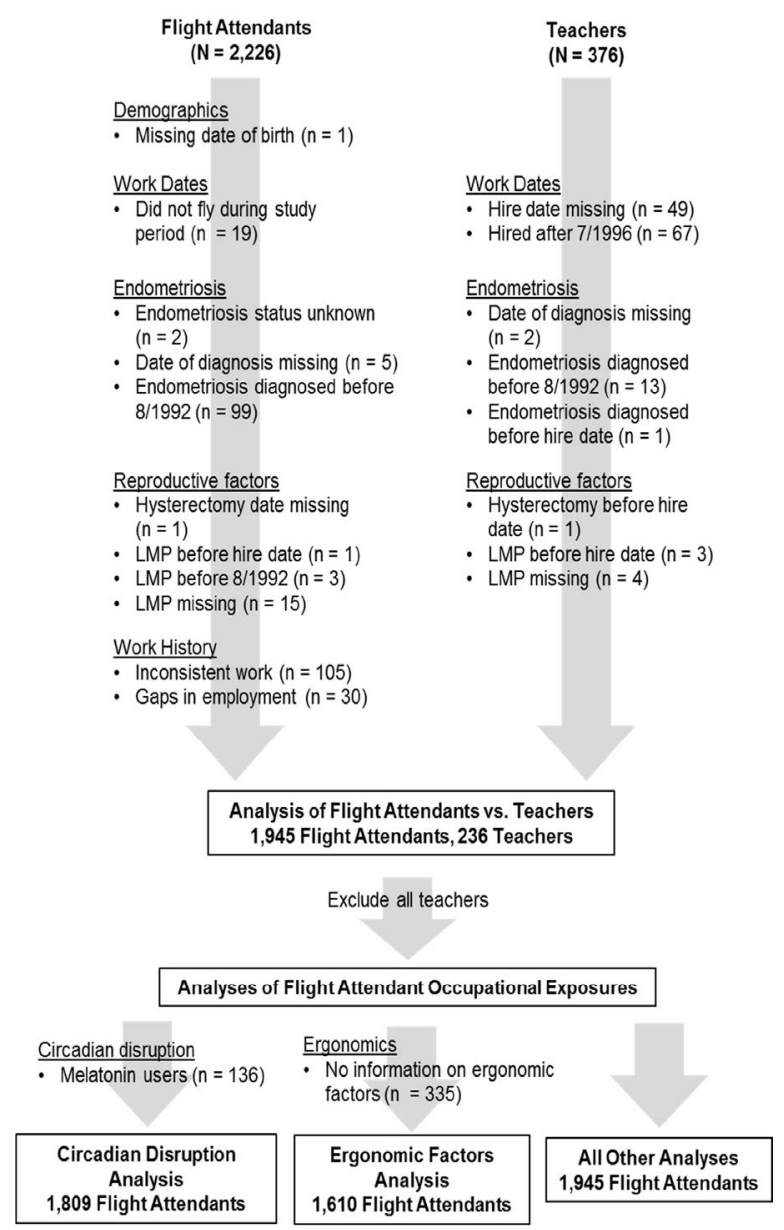

Figure 2. Reasons for exclusion of flight attendants and teachers from the analysis. Last menstrual period (LMP) is date of last menstrual period if menstrual periods have ceased.

the categories (categorical variables) in the regression model. If a continuous variable category had no upper bound (eg, >1.0), we used 1.5 times the lower bound.

There are few established risk factors for endometriosis, meaning that our choice of potential confounders to include in the model was driven in part by the literature and in part by the results of our bivariate analyses. Based on the existing literature, we included BMI as a potential confounder $(19,20)$. Based on associations seen in our data, we also considered study site, parity, and job tenure as potential confounders. However, using directed acyclic graphs (DAG) we found that parity was likely a collider and job tenure was likely a proxy for exposure; neither was a confounder and therefore we did not include them in the model. Age was implicitly taken into account in the model time scale. Women with missing values for BMI were excluded from adjusted models (10 flight attendants, 4 teachers).

First, we compared odds of endometriosis diagnosis between flight attendants and teachers. Then, we investigated occupational exposures and endometriosis, restricting the dataset to flight attendants only. This restriction was made because detailed exposure assessment was not available for radiation exposure, amount of work, and circadian disruption for teachers. In the analyses of circadian disruption (travel during sleep period, time zones crossed), we excluded 136 flight attendants who reported taking melatonin supplements within the past 12 months. In the analyses of ergonomic factors, we excluded 335 flight attendants who were no longer working as flight attendants during the interview period; the interview asked about ergonomic factors in the respondent's currently held job, not specifically her work as a flight attendant.

We conducted a sensitivity analysis in which we excluded women who had been employed for $<1$ year as a flight attendant or teacher during the study period (22 flight attendants, 24 teachers). This could be because they started their job late or left it early in the study period, or both. Information on the date the women left work was only available for the flight attendants and so our analysis assumes that teachers remained employed through 31 July 1996.

\section{Results}

Of the 5096 flight attendants contacted to participate in the study, 2595 were eligible for inclusion. For teachers, 1582 were contacted and 466 were eligible for inclusion. Among the 2226 (86\%) flight attendants and 376 (81\%) teachers who completed the interview, following exclusions, we included 1945 flight attendants (median of 94 person-months at risk, range: $2-105$ ) and 236 teachers (median 84 person-months at risk, range: 11-104) in our first analysis. A total of 99 laparoscopically-confirmed endometriosis cases were reported in the interview (91 among flight attendants, 8 among teachers).

Table 1 shows characteristics of the flight attendants and teachers in the study population. Compared to teachers, flight attendants were younger, had later age at menarche, lower BMI, higher income, were more likely to be nulliparous, were less likely to be of non-Hispanic white race/ethnicity, were more likely to be recruited from study site 2, and were more likely to have a job tenure of $0-4$ years. Flight attendants were no more likely to report endometriosis than teachers (adjusted OR 1.0, 95\% CI 0.5-2.2). In sensitivity analysis, after excluding women who worked for $<1$ year during the study period, the adjusted OR was 1.4 (95\% CI 0.5-3.5).

Among the 1945 flight attendants, women reporting an endometriosis diagnosis $(\mathrm{N}=91)$ had fewer pregnancies, were more likely to be recruited from study site 1 , and were more likely to have a longer job tenure than 
women who did not report an endometriosis diagnosis, but these groups were otherwise similar on other examined characteristics (table 2).

The total number of flight segments flown per year was associated with higher odds of endometriosis (adjusted OR 2.2, 95\% CI 1.1-4.2 for quartile 4 versus quartile $1, \mathrm{P}$ for trend $=0.04$ ) and a suggestive association was found for the median number of flight segments flown per flight day (adjusted OR 1.8, 95\% CI 0.9-3.9 for $>2.0$ versus 1.0 segments/day, $P$ for trend $=0.11$ ) (table 3 ). Another measure for amount of work aside from flight segments worked is block hours worked; block hours per year was not associated with endometriosis (adjusted OR $1.2,95 \%$ CI $0.6-2.2$ for quartile 4 versus quartile 1 ). No association was observed with time zones crossed per year, but there was a suggestive inverse association with time zones crossed per flight segment (adjusted OR 0.6, 95\% CI 0.2-1.6 for $>1.0$ versus 0 time zones/segment). There was also no linear association between average number of hours flown during the standard sleep hours and endometriosis, although the estimate for quartile 2 was elevated (adjusted OR 1.4, 95\% CI 0.8-2.5 for quartile 2 versus quartile $1, \mathrm{P}$ for trend $=0.85$ ). Because it could influence work schedule, we stratified the analysis by parity (nulliparous versus parous): there was insufficient sample size to derive stable estimates for nulliparous women only, and the results for parous women were similar to the results for all women (data not shown). Sensitivity analyses excluding women contributing $<1$ person-year during the study period yielded similar results to the original analysis (results not presented).

Absorbed dose radiation metrics appeared weakly associated with endometriosis, but not in a linear doseresponse fashion; the second and third quartiles often had the largest effect estimates (table 4). Low power and wide CI limited our ability to further interpret the results. The strongest associations were observed with muons (adjusted OR 1.5, 95\% CI 0.8-2.9, quartile 3 versus quartile $1, \mathrm{P}$ trend $=0.70$ ), electromagnetic showers (adjusted OR 1.4, 95\% CI 0.7-2.6 quartile 2 versus quartile 1 , $\mathrm{P}$ for trend $=0.80$ ), and protons (adjusted OR 1.5, 95\% CI 0.82.7 , quartile 3 versus quartile $1, \mathrm{P}$ trend $=0.88$ ) (table 4 ). Analyzing the radiation metrics as continuous variables or dichotomizing at the median did not change interpretation of results (data not shown). CI were also too wide for the analyses of ergonomic factors, which had the strongest associations with endometriosis for lifting (adjusted OR 1.5, 95\% CI 0.8-2.5, 6-10 versus 0-5 times/day, $\mathrm{P}$ trend $=0.09$ ), standing (adjusted OR 1.4, 95\% CI 0.9-2.2, $>8$ versus $0-8$ hours/day), and physical effort (adjusted OR 1.4, 95\% CI 0.7-2.6, P for trend=0.51) (table 5). Sensitivity analyses excluding women with $<1$ year of contributed person-time during the study period gave similar results (results not presented).

\section{Discussion}

In this study investigating occupational risk factors for endometriosis among flight attendants, our results suggest that flight attendants have no higher risk of endometriosis than a comparison group of teachers. However, among the flight attendants, a greater number of flight segments flown per year was associated with increased odds of endometriosis.

Flight attendants have a relatively low BMI on average compared to the general population and other occupational groups; low BMI is a strong risk factor for endometriosis, which could explain why endometriosis might appear more common among flight attendants than other occupational groups. Finding a suitable occupational group for comparison with flight attendants is a challenge, not only because of differences in BMI distributions but because occupational exposures experienced by flight attendants differ substantially from workers on the ground. Cosmic radiation, crossing multiple time zones, and working at aviation altitude are exposures found in few other occupations, making internal comparisons an appropriate choice for investigating these types of occupational exposures. However, in our analyses restricted to flight attendants, we found little variation in variables such as BMI and some ergonomic factors, making it difficult to fully explore potential associations between these variables and endometriosis.

We found a dose-response association between average number of flight segments flown per year and endometriosis, with a greater number of segments associated with a higher likelihood of an endometriosis diagnosis. There was no strong association between block hours, a potential marker for work hours, and endometriosis. However, block hours is an imperfect measure of total work hours, because it does not include pre- and postflight duties such as embarking and disembarking passengers. These activities might be a greater contributor to total work hours for flight attendants flying multiple short flights per day (eg, greater numbers of segments per day), but less so for those flying single long-haul flights. It is possible that flight attendants with symptomatic endometriosis might choose different flight schedules than flight attendants without endometriosis, meaning that the association we found between flight segments and endometriosis could be a result of and not a cause of endometriosis. Flight attendants with endometriosis were less likely to have children than those without endometriosis (29\% versus 16\% nulliparous), and differences in childcare needs could be another factor influencing work schedule. Working a greater number of flight segments per day might be a more stressful and less desirable flight schedule than the long-haul flights typically chosen by more senior flight attendants, but it 
Table 1. Characteristics of flight attendants and teachers.

\begin{tabular}{|c|c|c|c|c|c|}
\hline & \multicolumn{2}{|c|}{$\begin{array}{l}\text { Teachers } \\
(\mathrm{N}=236)\end{array}$} & \multicolumn{2}{|c|}{$\begin{array}{l}\text { Flight attendants } \\
\qquad(\mathrm{N}=1945)\end{array}$} & \multirow[b]{2}{*}{ P-value } \\
\hline & $\mathrm{N}$ & $\%$ & $\mathrm{~N}$ & $\%$ & \\
\hline Age at interview (years) & & & & & $<0.001$ \\
\hline$<35$ & 46 & 19 & 546 & 28 & \\
\hline $35-39$ & 55 & 23 & 741 & 38 & \\
\hline $40-44$ & 60 & 25 & 430 & 22 & \\
\hline$\geq 45$ & 75 & 32 & 228 & 12 & \\
\hline Age at menarche (years) & & & & & $<0.001$ \\
\hline$<12$ & 42 & 18 & 184 & 11 & \\
\hline $12-13$ & 147 & 63 & 878 & 54 & \\
\hline$\geq 14$ & 44 & 19 & 552 & 34 & \\
\hline Missing & 3 & & 331 & & \\
\hline Body mass index $\left(\mathrm{kg} / \mathrm{m}^{2}\right)$ & & & & & $<0.001$ \\
\hline Underweight & 1 & 0.4 & 135 & 7 & \\
\hline Normal weight & 136 & 59 & 1600 & 83 & \\
\hline Overweight & 50 & 22 & 186 & 10 & \\
\hline Obese & 45 & 19 & 14 & 0.7 & \\
\hline Missing & 4 & & 10 & & \\
\hline Household income (US\$) & & & & & $<0.001$ \\
\hline$<50000$ & 50 & 22 & 339 & 18 & \\
\hline $50000-74999$ & 91 & 39 & 495 & 26 & \\
\hline$\geq 75000$ & 91 & 39 & 1060 & 56 & \\
\hline Missing & 4 & & 51 & & \\
\hline Number of pregnancies & & & & & 0.04 \\
\hline 0 & 31 & 13 & 326 & 17 & \\
\hline 1 & 52 & 22 & 345 & 18 & \\
\hline 2 & 77 & 33 & 533 & 28 & \\
\hline$\geq 3$ & 73 & 31 & 730 & 38 & \\
\hline Missing & 3 & & 11 & & \\
\hline Race/ethnicity & & & & & 0.01 \\
\hline Non-Hispanic white & 208 & 88 & 1582 & 82 & \\
\hline Other & 28 & 12 & 356 & 18 & \\
\hline Missing & 0 & & 7 & & \\
\hline Study site & & & & & 0.003 \\
\hline 1 & 120 & 51 & 764 & 39 & \\
\hline 2 & 82 & 35 & 831 & 43 & \\
\hline 3 & 34 & 14 & 350 & 18 & \\
\hline Smoking status & & & & & 0.36 \\
\hline Current & 20 & 8 & 150 & 9 & \\
\hline Former & 56 & 24 & 320 & 20 & \\
\hline Never & 160 & 68 & 1152 & 71 & \\
\hline Missing & 0 & & 323 & & \\
\hline Job tenure as of 1 August & & & & & \\
\hline Hired after this date & 64 & 27 & 116 & 6 & $<0.001$ \\
\hline $0-4$ years & 51 & 22 & 1047 & 54 & \\
\hline $5-9$ years & 59 & 25 & 552 & 28 & \\
\hline$\geq 10$ years & 62 & 26 & 230 & 12 & \\
\hline
\end{tabular}

has the advantage of allowing the flight attendants to spend fewer nights away from home.

There was no linear association between absorbed dose radiation metrics and endometriosis among flight attendants, although CI were wide and did not exclude the possibility of weak or non-linear associations. Biological plausibility for this association comes from a study of ionizing radiation in rhesus monkeys, in which female monkeys were irradiated with various doses of ionizing radiation consisting of protons, $\mathrm{X}$-rays, and electrons (21). Over a 17 -year study period, $53 \%$ of irradiated monkeys developed endometriosis, compared to $26 \%$ of nonirradiated monkeys. However, radiation
Table 2. Characteristics of flight attendants reporting and not reporting endometriosis.

\begin{tabular}{|c|c|c|c|c|c|}
\hline & \multicolumn{2}{|c|}{$\begin{array}{l}\text { No endometriosis } \\
(\mathrm{N}=1854)\end{array}$} & \multicolumn{2}{|c|}{$\begin{array}{l}\text { Endometriosis } \\
\qquad(\mathrm{N}=91)\end{array}$} & \multirow[b]{2}{*}{ P-value } \\
\hline & $N$ & $\%$ & $\mathrm{~N}$ & $\%$ & \\
\hline Age at interview (years) & & & & & 0.73 \\
\hline$<35$ & 520 & 28 & 26 & 29 & \\
\hline $35-39$ & 709 & 38 & 32 & 35 & \\
\hline $40-44$ & 406 & 22 & 24 & 26 & \\
\hline$\geq 45$ & 219 & 12 & 9 & 10 & \\
\hline Age at menarche (years) & & & & & 0.34 \\
\hline$<12$ & 177 & 12 & 7 & 8 & \\
\hline $12-13$ & 826 & 54 & 52 & 62 & \\
\hline$\geq 14$ & 527 & 34 & 25 & 30 & \\
\hline Missing & 324 & & 7 & & \\
\hline Body mass index $\left(\mathrm{kg} / \mathrm{m}^{2}\right)$ & & & & & 0.17 \\
\hline Underweight & 131 & 7 & 4 & 4 & \\
\hline Normal weight & 1517 & 82 & 83 & 91 & \\
\hline Overweight & 182 & 10 & 4 & 4 & \\
\hline Obese & 14 & 0.8 & 0 & 0 & \\
\hline Missing & 10 & & 0 & & \\
\hline Household income (US\$) & & & & & 0.65 \\
\hline$<50,000$ & 326 & 18 & 13 & 14 & \\
\hline $50,000-74,999$ & 470 & 26 & 25 & 27 & \\
\hline$\geq 75,000$ & 1007 & 56 & 53 & 58 & \\
\hline Missing & 51 & & 0 & & \\
\hline Number of pregnancies & & & & & $<0.01$ \\
\hline 0 & 299 & 16 & 27 & 30 & \\
\hline 1 & 324 & 18 & 21 & 23 & \\
\hline 2 & 508 & 28 & 25 & 27 & \\
\hline$\geq 3$ & 712 & 39 & 18 & 20 & \\
\hline Missing & 11 & & 0 & & \\
\hline Race/ethnicity & & & & & 0.30 \\
\hline Non-Hispanic white & 1504 & 81 & 78 & 86 & \\
\hline Other & 343 & 19 & 13 & 14 & \\
\hline Missing & 7 & & 0 & & \\
\hline Study site & & & & & 0.05 \\
\hline 1 & 718 & 39 & 46 & 51 & \\
\hline 2 & 796 & 43 & 35 & 38 & \\
\hline 3 & 340 & 18 & 10 & 11 & \\
\hline Smoking status & & & & & 0.50 \\
\hline Current & 143 & 9 & 7 & 8 & \\
\hline Former & 307 & 20 & 13 & 16 & \\
\hline Never & 1087 & 71 & 65 & 76 & \\
\hline Missing & 317 & & 6 & & \\
\hline Job tenure as of 1 August 1992 & & & & & $<0.01$ \\
\hline Hired after this date & 111 & 6 & 5 & 5 & \\
\hline $0-4$ years & 1002 & 54 & 45 & 49 & \\
\hline $5-9$ years & 514 & 28 & 38 & 42 & \\
\hline$\geq 10$ years & 227 & 12 & 3 & 3 & \\
\hline
\end{tabular}

in this experiment was of a higher dose and different composition than exposures aboard commercial aircraft, and, therefore, we might not expect the cosmic radiation experienced by flight attendants to have the same effect.

The biologic mechanism by which endometriosis occurs remains unknown. Several hypotheses exist, including retrograde menstruation (menstrual fluid and endometrial cells escape into the abdominal cavity, causing endometrial lesions), hormonal imbalances, and immune deficiencies (3). It is possible that occupational exposures could increase risk for endometriosis development, cause an earlier onset, or cause more severe symptoms. Endometriosis is a challenging outcome to 
Table 3. Associations between work characteristics, circadian disruption, and endometriosis. [ $95 \% \mathrm{Cl}=95 \%$ confidence interval; $\mathrm{N}=$ number of flight attendants (including all endometriosis cases); $O R_{\text {adj }}=$ odds ratio; $Q=$ quartile]

\begin{tabular}{|c|c|c|c|c|c|c|c|}
\hline & $\mathrm{N}$ & $0 \mathrm{R}_{\text {crude }}$ & $95 \% \mathrm{Cl}$ & $\mathrm{P}$-value & $0 \mathrm{R}_{\mathrm{adj}}{ }^{\mathrm{a}}$ & $95 \% \mathrm{Cl}$ & P-value \\
\hline Average block & & & & $0.13^{b}$ & & & $0.38^{\mathrm{b}}$ \\
\hline Q1 (26-455) & 486 & 1.0 & Ref & & 1.0 & Ref & \\
\hline Q2 (456-631) & 487 & 1.0 & $0.6-2.0$ & & 1.0 & $0.6-2.0$ & \\
\hline Q3 (632-754) & 486 & 1.1 & $0.6-2.1$ & & 1.1 & $0.6-2.1$ & \\
\hline Q4 (755-1279) & 486 & 1.4 & $0.8-2.5$ & & 1.2 & $0.6-2.2$ & \\
\hline $\begin{array}{l}\text { Average flight } \\
\text { segments per } \\
\text { year }\end{array}$ & & & & $0.05^{b}$ & & & $0.02^{b}$ \\
\hline Q1 (8-163) & 484 & 1.0 & Ref & & 1.0 & Ref & \\
\hline Q2 (164-243) & 487 & 1.6 & $0.8-3.2$ & & 1.5 & $0.8-3.1$ & \\
\hline Q3 (244-315) & 488 & 1.7 & $0.9-3.4$ & & 1.8 & $0.9-3.5$ & \\
\hline Q4 (316-585) & 486 & 2.0 & $1.0-3.8$ & & 2.2 & $1.1-4.2$ & \\
\hline $\begin{array}{l}\text { Median flight } \\
\text { segments per } \\
\text { day }\end{array}$ & & & & $0.55^{b}$ & & & $0.11^{\mathrm{b}}$ \\
\hline 1.0 & 426 & 1.0 & Ref & & 1.0 & Ref & \\
\hline $1.1-2.0$ & 1077 & 1.0 & $0.6-1.7$ & & 1.2 & $0.7-2.1$ & \\
\hline$>2.0$ & 442 & 1.2 & $0.6-2.2$ & & 1.8 & $0.9-3.9$ & \\
\hline $\begin{array}{l}\text { Average hours } \\
\text { flown in stan- } \\
\text { dard sleep inter- } \\
\text { val per year c }\end{array}$ & & & & $0.49^{b}$ & & & $0.85^{b}$ \\
\hline Q1 (2-50) & 453 & 1.0 & Ref & & 1.0 & Ref & \\
\hline Q2 (51-78) & 452 & 1.3 & $0.7-2.3$ & & 1.4 & $0.8-2.5$ & \\
\hline Q3 (79-120) & 452 & 0.9 & $0.5-1.8$ & & 0.9 & $0.5-1.8$ & \\
\hline Q4 (121-654) & 452 & 1.0 & $0.5-1.9$ & & 0.9 & $0.5-1.7$ & \\
\hline $\begin{array}{l}\text { Average time } \\
\text { zones crossed } \\
\text { per year c }\end{array}$ & & & & $0.75^{b}$ & & & $0.49 \mathrm{~b}$ \\
\hline Q1 (0-98) & 452 & 1.0 & Ref & & 1.0 & Ref & \\
\hline Q2 (99-188) & 452 & 1.1 & $0.6-2.2$ & & 0.9 & $0.4-1.9$ & \\
\hline Q3 (189-264) & 452 & 1.4 & $0.8-2.7$ & & 1.1 & $0.5-2.4$ & \\
\hline Q4 (265-811) & 453 & 1.4 & $0.8-2.7$ & & 1.0 & $0.5-2.3$ & \\
\hline $\begin{array}{l}\text { Median time } \\
\text { zones per flight } \\
\text { segment }{ }^{c}\end{array}$ & & & & $0.72^{d}$ & & & $0.34 d$ \\
\hline 0 & 917 & 1.0 & Ref & & 1.0 & Ref & \\
\hline $0.1-1.0$ & 726 & 1.3 & $0.8-2.0$ & & 0.9 & $0.5-1.5$ & \\
\hline$>1.0$ & 166 & 0.9 & $0.4-2.0$ & & 0.6 & $0.2-1.6$ & \\
\hline
\end{tabular}

${ }^{a}$ Adjusted for body mass index (continuous variable) and study site.

${ }^{b}$ Midpoint of category used to calculate P-value for linear trend.

c Restricted to flight attendants reporting no melatonin use in the past 12 months.

d Midpoint of category used to calculate P-value for linear trend for lower 2 categories; 1.5 times the lower bound used for the $3^{\text {rd }}$ category.

evaluate in epidemiologic studies because several years can elapse between onset of symptoms and diagnosis, and many cases are never diagnosed (22). In our data, 75 (76\%) of the 99 endometriosis cases occurred within five years of the start of the study period and $100 \%$ within eight years. If we had access to earlier flight records, it might have been feasible to incorporate a lag time into our analysis to explore further the impact of delayed diagnosis. Our measured outcome is therefore more accurately described as rate of diagnosis rather than disease. If any of our exposures are associated with healthcare-seeking behavior or timing of diagnosis, we might mistakenly
Table 4. Associations between average annual absorbed radiation dose ( $\mu \mathrm{Gy} / \mathrm{year}$ ) and endometriosis. [95\% Cl=95\% confidence interval; $\mathrm{OR}_{\mathrm{adj}}=$ adjusted odds ratio; $\mathrm{Q}=$ quartile]

\begin{tabular}{|c|c|c|c|c|c|c|}
\hline & N & $\mathrm{OR}_{\text {crude }}$ & $95 \% \mathrm{Cl}$ & P-value & $0 \mathrm{R}_{\mathrm{adj}}{ }^{\mathrm{a}}$ & $95 \% \mathrm{Cl}$ P-value \\
\hline Total radiation ${ }^{\mathrm{c}}$ & & & & $0.55^{b}$ & & $0.88^{b}$ \\
\hline Q1 (25-466) & 487 & 1.0 & Ref & & 1.0 & Ref \\
\hline Q2 (467-638) & 486 & 1.3 & $0.7-2.4$ & & 1.3 & $0.7-2.4$ \\
\hline Q3 (639-828) & 485 & 1.2 & $0.7-2.3$ & & 1.2 & $0.6-2.2$ \\
\hline Q4 (829-2094) & 487 & 1.3 & $0.7-2.3$ & & 1.0 & $0.5-1.9$ \\
\hline Neutrons & & & & $0.66^{b}$ & & $0.92^{b}$ \\
\hline Q1 (5-101) & 486 & 1.0 & Ref & & 1.0 & Ref \\
\hline Q2 (102-139) & 486 & 1.1 & $0.6-2.0$ & & 1.1 & $0.6-2.0$ \\
\hline Q3 (140-175) & 487 & 1.3 & $0.7-2.4$ & & 1.3 & $0.7-2.3$ \\
\hline Q4 (175-490) & 486 & 1.2 & $0.7-2.2$ & & 1.1 & $0.6-2.0$ \\
\hline Muons & & & & $0.41^{b}$ & & $0.70^{b}$ \\
\hline Q1 (2-49) & 486 & 1.0 & Ref & & 1.0 & Ref \\
\hline Q2 (50-68) & 485 & 1.3 & $0.7-2.4$ & & 1.3 & $0.7-2.4$ \\
\hline Q3 (69-82) & 488 & 1.5 & $0.8-2.8$ & & 1.5 & $0.8-2.9$ \\
\hline Q4 (83-185) & 486 & 1.3 & $0.7-2.5$ & & 1.2 & $0.6-2.3$ \\
\hline $\begin{array}{l}\text { Electromagnetic } \\
\text { showers }\end{array}$ & & & & $0.53^{b}$ & & $0.80^{b}$ \\
\hline Q1 (13-254) & 486 & 1.0 & Ref & & 1.0 & Ref \\
\hline Q2 (255-351) & 486 & 1.3 & $0.7-2.5$ & & 1.4 & $0.7-2.6$ \\
\hline Q3 (352-467) & 487 & 1.4 & $0.7-2.5$ & & 1.3 & $0.7-2.4$ \\
\hline Q4 (468-1147) & 486 & 1.3 & $0.7-2.5$ & & 1.0 & $0.5-2.0$ \\
\hline Protons & & & & $0.61^{b}$ & & $0.88^{b}$ \\
\hline Q1 (2-53) & 487 & 1.0 & Ref & & 1.0 & Ref \\
\hline Q2 (54-73) & 486 & 1.1 & $0.6-2.1$ & & 1.1 & $0.6-2.2$ \\
\hline Q3 (74-94) & 485 & 1.5 & $0.8-2.8$ & & 1.5 & $0.8-2.7$ \\
\hline Q4 (95-257) & 487 & 1.2 & $0.6-2.2$ & & 1.0 & $0.5-1.9$ \\
\hline Pions & & & & $0.50^{b}$ & & $0.93^{b}$ \\
\hline Q1 (0.2-3.9) & 489 & 1.0 & Ref & & 1.0 & Ref \\
\hline Q2 (4.0-5.3) & 484 & 1.2 & $0.7-2.3$ & & 1.2 & $0.7-2.3$ \\
\hline Q3 (5.4-6.9) & 486 & 1.2 & $0.7-2.3$ & & 1.2 & $0.7-2.2$ \\
\hline Q4 (7.0-16.4) & 486 & 1.3 & $0.7-2.4$ & & 1.1 & $0.6-2.0$ \\
\hline
\end{tabular}

a Adjusted for body mass index (continuous variable) and study site.

${ }^{b}$ Midpoint of category used to calculate P-value for linear trend.

c The average yearly effective dose total radiation among flight attendants in this population had a median of 1472 microsieverts $(\mu \mathrm{Sv})$ and a range of $57-5032 \mu \mathrm{Sv}$ using proton weighting factor $=2$. Effective dose is commonly used in studies of radiation protection.

conclude that these are risk factors for endometriosis. This might have occurred when we excluded 112 women because their diagnosis was before the study start date. Delays in diagnosis of endometriosis might mean that women who were quickly diagnosed with endometriosis are more likely to have been excluded, whereas women whose endometriosis was diagnosed after several years might be more likely to have been included. We did not have any information on the symptoms experienced by women with endometriosis, when they first began, or their severity, and we did not know if endometriosis was diagnosed based on symptoms or as a part of another medical evaluation (eg, infertility). Because we relied on self-report of laparoscopically confirmed endometriosis (in contrast to studies that include only women who have surgical confirmation of presence or absence of endometriosis), we expect misclassification of outcome 
Table 5. Associations between ergonomic factors and endometriosis. [ $95 \% \mathrm{Cl}=95 \%$ confidence interval; $\mathrm{N}=$ number of flight attendants (including all endometriosis cases); $\mathrm{OR}_{\mathrm{adj}}=$ adjusted odds ratio].

\begin{tabular}{|c|c|c|c|c|c|c|c|}
\hline & $\mathrm{N}$ & $\mathrm{OR}_{\text {crude }}$ & $95 \% \mathrm{Cl}$ & P-value & $O R_{a d j}{ }^{a}$ & $95 \% \mathrm{Cl}$ & P-value \\
\hline $\begin{array}{l}\text { Lifting } \geq 15 \mathrm{lbs} \\
\text { (times/day) }\end{array}$ & & & & $0.11^{b}$ & & & $0.09 \mathrm{~b}$ \\
\hline $0-5$ & 357 & 1.0 & Ref & & 1.0 & Ref & \\
\hline $6-10$ & 560 & 1.5 & $0.9-2.6$ & & 1.5 & $0.8-2.5$ & \\
\hline$>10$ & 693 & 0.7 & $0.4-1.3$ & & 0.7 & $0.4-1.3$ & \\
\hline $\begin{array}{l}\text { Standing } \\
\text { (hours/day) }\end{array}$ & & & & . b & & &. $\mathrm{b}$ \\
\hline $0-8$ & 555 & 1.0 & Ref & & 1.0 & Ref & \\
\hline$>8$ & 1055 & 1.4 & $0.9-2.2$ & & 1.4 & $0.9-2.2$ & \\
\hline $\begin{array}{l}\text { Bending } \\
\text { (times/day) }\end{array}$ & & & & $0.42^{b}$ & & & $0.46^{b}$ \\
\hline $0-50$ & 567 & 1.0 & Ref & & 1.0 & Ref & \\
\hline $51-75$ & 365 & 1.0 & $0.6-1.7$ & & 1.0 & $0.6-1.7$ & \\
\hline$>75$ & 678 & 0.8 & $0.5-1.3$ & & 0.8 & $0.5-1.4$ & \\
\hline $\begin{array}{l}\text { Pushing and } \\
\text { pulling (times/ } \\
\text { day) }\end{array}$ & & & & $0.17^{\mathrm{b}}$ & & & $0.17^{\mathrm{b}}$ \\
\hline $0-19$ & 490 & 1.0 & Ref & & 1.0 & Ref & \\
\hline $20-30$ & 327 & 0.9 & $0.5-1.6$ & & 0.9 & $0.5-1.6$ & \\
\hline$>30$ & 793 & 0.7 & $0.4-1.2$ & & 0.7 & $0.4-1.2$ & \\
\hline $\begin{array}{l}\text { Overall } \\
\text { physical effort }\end{array}$ & & & & $0.42^{c}$ & & & $0.51^{c}$ \\
\hline $\begin{array}{l}\text { Light, } \\
\text { moderate }\end{array}$ & 575 & 1.0 & Ref & & 1.0 & Ref & \\
\hline $\begin{array}{l}\text { Somewhat } \\
\text { hard }\end{array}$ & 832 & 1.0 & $0.6-1.6$ & & 0.9 & $0.6-1.5$ & \\
\hline Very hard & 203 & 1.4 & $0.8-2.7$ & & 1.4 & $0.7-2.6$ & \\
\hline
\end{tabular}

a Adjusted for body mass index (continuous variable) and study site.

${ }^{b}$ Midpoint of category used to calculate $P$ for linear trend when upper boundary for the category was defined; 1.5 times the lower bound used when there was no upper boundary. P for trend are only presented for variables with $\geq 3$ categories.

c Ordinal value corresponding to categories used to calculate P-value for linear trend

in our study. Although we attempted to create a cohort of women at risk for endometriosis at study baseline, it is possible that some of our incident endometriosis diagnoses were prevalent cases that had not yet been diagnosed. We would not expect substantial bias if the prevalence of prevalent cases does not differ by exposure status.

A unique strength of our study was the use of individual flight records for exposure assessment instead of proxy measures or self-reported exposures. This more precise exposure assessment reduced our chance of bias from nondifferential or differential exposure measurement error. A previous report showed that flight attendants tend to over-report their number of block hours and flight segments when compared to company records (23), and similar measurement error is likely for our other self-reported exposures. Flight records afforded us a level of detail that would be difficult to achieve using proxy or self-reported measures.

A limitation of our exposure assessment is that flight records were only available for a 4-year period, 1992-1996. We assumed that the exposures during this period were representative of the flight attendants' usual exposures over her career. However, flight attendants' work patterns change over time; for example, flight attendants with seniority are more likely to fly longer overseas flights than colleagues with shorter job tenure. We excluded 135 flight attendants because their 4-year work histories were too inconsistent to reliably create annual metrics; however, the prevalence of endometriosis was similar in this excluded group ( $\mathrm{N}=4,3.0 \%)$ and the included women $(\mathrm{N}=99,4.5 \%)$.

We assumed that the information collected on ergonomic factors during the interviews in 1999-2001 was representative of the flight attendants' exposures during the time they were at risk for endometriosis. Ergonomic conditions might have changed since the time of the interview in 1999-2001 to present day, and results might not be generalizable to current flight attendants' work. Because date of endometriosis diagnosis was before the time of the interview (ie, information on both exposure and outcome were collected at the same time), recall bias is possible for exposures collected after endometriosis had already been diagnosed. If women with endometriosis were more likely to recall greater ergonomic exposures, we might expect bias away from the null. Given that most of our results for ergonomic exposures were null, this is an unlikely explanation for our results. Endometriosis symptoms also might cause women to avoid certain ergonomic exposures such as heavy lifting or standing for prolonged periods, meaning that exposures measured after endometriosis symptom onset might not be representative of exposures experienced before onset. This could disrupt detection of possible dose-response relationships, resulting in stronger associations being observed between lower ergonomic exposures than higher ones. For example, our results for standing had the greatest association with endometriosis in the middle category and an inverse association in the highest category; however, the wide $\mathrm{CI}$ makes it difficult to interpret these results.

In this study, we found that flight attendants were no more likely than teachers to report endometriosis. Flight attendants flying a greater number of segments per year and per day were more likely to report an endometriosis diagnosis than those flying fewer segments. Better understanding of the reasons for this association will necessitate both more insight into the work schedules or environments of flight attendants flying the greatest number of segments and further information on how an endometriosis diagnosis might affect a flight attendants' work scheduling.

\section{Acknowledgements}

The findings and conclusions of this report are those of the authors and do not necessarily represent the views of 
the Centers for Disease Control and Prevention.

We thank the women who participated in this study. We appreciate the assistance of the study airlines and the school districts; Airlines for America; the Federal Aviation Administration; the Association of Flight Attendants, its Seattle Local 19, and Judith Anderson of the Air Safety, Health and Security Department for consultation; the Association of Professional Flight Attendants and its Miami representatives; the International Brotherhood of Teamsters, Airline Division, and its Detroit representatives; and the American Federation of Teachers and National Education Association and their local affiliates (Seattle Education Association, Grand Rapids Education Association, United Teachers of Dade, and Pinellas Classroom Teachers Association).

\section{References}

1. Whiteman MK, Kuklina E, Jamieson DJ, Hillis SD, Marchbanks PA. Inpatient hospitalizations for gynecologic disorders in the United States. Am J Obstet Gynecol. 2010;202:541.e1-e6.

2. D'Hooghe T, Hill JAI. Endometriosis. In: Berek JS, ed. Berek and Novak's Gynecology, Fourteenth Edition. Philadelphia: Lippincott Williams \& Wilkins; 2007:1137-84.

3. Missmer SA, Cramer DW. The epidemiology of endometriosis. Obstet Gynecol Clin North Am. 2003;30:1-19. http://dx.doi. org/10.1016/S0889-8545(02)00050-5.

4. Nnoaham KE, Hummelshoj L, Webster P, d'Hooghe T, de Cicco Nardone F, de Cicco Nardone C, et al. Impact of endometriosis on quality of life and work productivity: a multicenter study across ten countries. Fertil Steril. 2011;96:366-73. http:// dx.doi.org/10.1016/j.fertnstert.2011.05.090.

5. Hediger ML, HartnettHJ,Louis GM.Association of endometriosis with body size and figure. Fertil Steril. 2005;84:1366-76. http:// dx.doi.org/10.1016/j.fertnstert.2005.05.029.

6. Yi KW, Shin JH, Park MS, Kim T, Kim SH, Hur JY. Association of body mass index with severity of endometriosis in Korean women. Int J Gynaecol Obstet. 2009;105:39-42. http://dx.doi.org/10.1016/j.ijgo.2008.11.001.

7. Vitonis AF, Baer HJ, Hankinson SE, Laufer MR, Missmer SA. A prospective study of body size during childhood and early adulthood and the incidence of endometriosis. Hum Reprod. 2010;25:1325-34. http://dx.doi.org/10.1093/humrep/deq039.

8. Marino JL, Holt VL, Chen C, Davis S. Lifetime occupational history and risk of endometriosis. Scand J Work Environ Health. 2009;35:233-40. http://dx.doi.org/10.5271/sjweh.1317.

9. Griffiths RF, Powell DM. The occupational health and safety of flight attendants. Aviat Space Environ Med. 2012;83:514-21. http://dx.doi.org/10.3357/ASEM.3186.2012.

10. Marino JL, Holt VL, Chen C, Davis S. Shift work, hCLOCK T3111C polymorphism, and endometriosis risk. Epidemiology. 2008;19:477-84. http://dx.doi.org/10.1097/ EDE.0b013e31816b7378.
11. Schernhammer ES, Vitonis AF, Rich-Edwards J, Missmer SA. Rotating shiftwork and the risk of endometriosis in premenopausal women. Am J Obstet Gynecol. 2011;205:476. e1-e8.

12. Grajewski B, Whelan EA, Lawson CC, Hein MJ, Waters MA, Anderson JL, et al. Miscarriage among flight attendants. Epidemiology. 2015;26:192-203. http://dx.doi.org/10.1097/ EDE.0000000000000225.

13. Whelan EA, Grajewski B, Wood E, Kwan L, Nguyen M, Schnorr $\mathrm{TM}$, et al. Feasibility issues in reproductive biomonitoring of female flight attendants. J Occup Environ Med. 2002;44:947-55. http://dx.doi.org/10.1097/00043764-200210000-00014.

14. Grajewski B, Nguyen MM, Whelan EA, Cole RJ, Hein MJ. Measuring and identifying large-study metrics for circadian rhythm disruption in female flight attendants. Scand J Work Environ Health. 2003;29:337-46. http://dx.doi.org/10.5271/ sjweh. 740 .

15. Grajewski B, Waters MA, Yong LC, Tseng CY, Zivkovich Z, Casinelli II RT. Airline pilot cosmic radiation and circadian disruption exposure assessment from logbooks and company records. Ann Occup Hyg. 2011;55:465-75. http://dx.doi. org/10.1093/annhyg/mer024.

16. Friedberg W, Copeland K. What aircrews should know about their occupational exposure to ionizing radiation. Oklahoma City: Feceral Aviation Administrion; 2003.

17. Grajewski B, Waters MA, Whelan EA, Bloom TF. Radiation dose estimation for epidemiologic studies of flight attendants. Am J Ind Med. 2002;41:27-37. http://dx.doi.org/10.1002/ ajim. 10018 .

18. Anderson JL, Mertens CJ, Grajewski B, Luo L, Tseng CY, Casinelli II RT. Flight attendant radiation dose from solar particle events. Aviat Space Environ Med. 2014;85:826-32. http://dx.doi.org/10.3357/ASEM.3989.2014.

19. Lafay Pillet MC, Schneider A, Borghese B, Santulli P, Souza $\mathrm{C}$, Streuli I, et al. Deep infiltrating endometriosis is associated with markedly lower body mass index. Hum Reprod. 2012;27:265-72. http://dx.doi.org/10.1093/humrep/der346.

20. Shah DK, Correia KF, Vitonis AF, Missmer SA. Body size and endometriosis: results from 20 years of follow-up within the Nurses' Health Study II prospective cohort. Hum Reprod. 2013;28:1783-92. http://dx.doi.org/10.1093/humrep/det120.

21. Fanton JW, Golden JG. Radiation-induced endometriosis in Macaca mulatta. Radiat Res. 1991;126:141-6. http://dx.doi. org/10.2307/3577812.

22. Greene R, Stratton P, Cleary SD, Ballweg ML, Sinaii N. Diagnostic experience among 4,334 women reporting surgically diagnosed endometriosis. Fertil Steril. 2009;91:329. http://dx.doi.org/10.1016/j.fertnstert.2007.11.020.

23. Grajewski B, Atkins DJ, Whelan EA. Self-reported flight hours vs. company records for epidemiologic studies of flight attendants. Aviat Space Environ Med. 2004;75:806-10.

Received for publication: 28 July 2015 